\title{
Determination of the Intervention Strategies for the Prevention of Fetal Macrosomia Dependent Cesarean Sections in Nigeria
}

\author{
Ute Inegbenebor ${ }^{*}$ \\ Department of Physiology, Faculty of Basic Medical Sciences, College of Medicine, Ambrose Alli University, Ekpoma Nigeria \\ *Corresponding author: druteinegbenebor@yahoo.com
}

\begin{abstract}
Background: Subsequent to the rising cesarean section rates worldwide over the past three decades, this study was done to determine the risk factors that predispose to fetal macrosomia with the aim of determining the intervention strategies for preventing fetal macrosomia dependent cesarean sections in Nigeria. Subjects and Methods: A record review of the birth weights of 2410 babies delivered in St Philomena's Hospital, a survey of the nutritional habits of 75 mothers of macrosomic babies attending postnatal clinic within the study period, and an assessment of the level of awareness' of the fasting blood glucose status of 75 mothers of macrosomic babies and 330 pregnant women with interviewer administered questionnaire were done. Results: The prevalence rate for fetal macrosomia in St Philomena's Hospital was 8.4\% during the study period. Cesarean section rate among women with fetal macrosomia was $39.2 \%$ compared to a rate of $18 \%$ in women who gave birth to babies with normal birth weight. It was also found that most pregnant women and mothers of macrosomic babies were not aware of their fasting blood glucose status. Majority of mothers of macrosomic babies preferred high glycemic index diets and also consumed sugary beverages on daily basis. Conclusion: Fetal macrosomia is a preventable outcome of pregnancy in the presence of moderate dietary restriction, low glycemic index diets as well as the inclusion of dietary fiber in the diet of pregnant women. Furthermore, a lower incidence of fetal macrosomia is capable of reducing cesarean section rates in Nigeria.
\end{abstract}

Keywords: prevention, macrosomia, cesarean sections, Nigeria

Cite This Article: Ute Inegbenebor, "Determination of the Intervention Strategies for the Prevention of Fetal Macrosomia Dependent Cesarean Sections in Nigeria." American Journal of Public Health Research, vol. 5, no. 3 (2017): 56-62. doi: 10.12691/ajphr-5-3-2.

\section{Introduction}

Cesarean section rates have escalated in all parts of the world in the last thirty years or more. Since 1985, the international healthcare community has considered the ideal rate for caesarean sections to be between $10 \%$ and $15 \%$. Since then, caesarean sections have become increasingly common in both developed and developing countries. [1] Common indications for cesarean section include cephalo-pelvic disproportion, obstructed labor, imminent uterine rupture, prolonged labor, cervical dystocia, mal-presentation, fetal distress, placenta previa, cord compression, fetal macrosomia and two previous cesarean sections. Other indications include conditions where other complications, such as breech presentation, fetal macrosomia and severe preeclampsia/eclampsia, are presenting in labor in a woman who has had a previous uterine scar. [2]

Cesarean section rates have risen to almost $50 \%$ in China, [3] 50\% in Brazil, [4] 32\% in U.S.A, [5] and variable rates of $14.3-35.5 \%$ in the various geopolitical regions of Nigeria $[6,7,8,9,10]$. Though the international health community has recommended that every effort should be made to provide cesarean section for women in need rather than striving to achieve specific rates, there are long and short term risks for cesarean sections, especially when they are carried out by health care providers in settings that lack the facilities and/or capacity to properly conduct safe surgery and treat surgical complications as are commonly found in developing countries such as Nigeria. [1]

Cesarean section rates have increased astronomically in the past thirty years for several reasons. These include non-medical factors, [11] fear of litigation, [12] perceived safety of cesarean section in comparison to vaginal birth [3] and assurance of survival for precious baby, [13] pressure from patients and family members, [11] financial gain $[14,15]$ and medical factors such as poor management, and lack of knowledge of partograph and lack of knowledge of the use of forceps and vacuum extractor. [16] Cesarean section may be demanded by women who want give birth on particular days of the year [15] and some doctors may succumb to pressure from these women. The fear of litigation is the cause of high cesarean rates in the United States of America [12] while the assurance of survival of the baby is the reason for the high rate in China where there is restriction on child birth. [3] Pressure from patients and family members, who want to avoid the stress 
of labor may force some doctors to resort to cesarean section. [16] In some countries, doctors prefer to perform a cesarean section since it takes a shorter period and yields higher financial gain [16] than a labor process. In several cases, poor management is characterized by watchful expectancy, lack of knowledge of the use of partograph, forceps or vacuum extractor by doctors in district hospitals [16].

Some of the factors that contribute to the stupendous increase in cesarean section rates are preventable. One of these factors is fetal macrosomia. This study was therefore carried out to determine the risk factors that predispose to fetal macrosomia with the aim of determining the intervention strategies for preventing fetal macrosomia dependent cesarean sections in Nigeria.

\section{Materials and Methods}

\subsection{Ethical Consideration}

Permission for this study was obtained from the ethical committee of St Philomena's Hospital, Benin City, Nigeria.

\subsection{Background of the Study Population}

Benin City, the headquarters of Edo state of Nigeria has a projected population of 1.6 million people. [17] Though it is inhabited by approximately half of the population in Edo State, it is made up of only 3 out of the 18 local government areas of Edo State. These Local Government areas are Oredo, Egor and Ikpoba-Okha.

Benin City has several public and private hospitals, among which, are 2 state government owned tertiary hospitals, a federal government owned tertiary (teaching hospital) and 2 prominent missionary hospitals. Each of these hospitals has facilities for maternal health activities of Antenatal care, Clean and Safe Delivery, Post Natal Care and Family planning. However, several pregnant women prefer the catholic mission hospital named St Philomena's Hospital for antenatal care and delivery. This study was therefore conducted in St Philomena's Hospital in Benin City, Nigeria.

\subsection{Research Design}

This study consisted of three components: Retrospective study, Retrospective cohort study and Prospective study.

\subsection{Retrospective Study}

This was a survey of the birth weights and cesarean births of new born babies using a record review of 2410 deliveries in St Philomena's Hospital, Benin City from April 2014 to March 2016.

\subsection{Retrospective Cohort Study}

This was a survey of 75 mothers of macrosomic babies, who attended post natal clinic in St Philomena's Hospital from January to March 2016 to find out their nutritional habits during pregnancy and knowledge of their glucose tolerance status during pregnancy, using an interviewer administered questionnaire.

\subsection{Prospective Study}

This was a study of the knowledge of glucose tolerance status of 330 pregnant women attending antenatal clinic in St Philomena's Hospital, Benin City from January to March, 2016 using an interviewer administered questionnaire.

\subsubsection{Determination of Sample Size [18]}

The desired sample size when population is more than 10,000 is as follows:

$$
\mathrm{n}=\frac{z^{2} \mathrm{pq}}{\mathrm{d}^{2}}
$$

where $\mathrm{n}$ is the desired sample size when population is more than 10,000

$\mathrm{z}$ is the standard normal deviation set at 1.96, which corresponds to $95 \%$ confidence level

$\mathrm{p}$ is the proportion in the particular population estimated to have a particular characteristic (eg. 5.4\% prevalence for fetal macrosomia in Benin City. [19]

$\mathrm{q}$ is $1.0-\mathrm{p}$ e.g 0.946

$\mathrm{d}$ is the degree of accuracy desired. Usually set at 0.05 or 0.02 .

Applying the values in this study

$$
\mathrm{n}=\frac{1.96^{2} * 0.054 * 0.946}{(0.05)^{2}}=78.49=78
$$

\subsubsection{Determination of Sample Size for Mothers Attending Postnatal Clinic [18]}

Since the population of pregnant women who deliver their babies in St Philomena's Hospital is less than 10,000.

The sample size for this study will be

$$
\mathrm{nf}=\frac{\mathrm{n}}{1+(\mathrm{n} / \mathrm{N})}
$$

Where $\mathrm{nf}$ is the desired sample size when population is less than 10,000

$\mathrm{n}$ is the desired sample size when population is more than 10,000

$\mathrm{N}$ is the estimate of the population size

Applying the values for these estimates,

$$
\mathrm{nf}=\frac{78}{1+78 / 2000}=78 / 1.039=75.072
$$

Therefore the desired sample size for mothers attending postnatal clinic is 75 .

\subsubsection{Determination of Sample Size for Pregnant Women Attending Antenatal Clinic [18]}

The desired sample size when population is more than 10,000 as follows:

$$
\mathrm{n}=\frac{z^{2} \mathrm{pq}}{\mathrm{d}^{2}}
$$

Where $\mathrm{n}$ is the desired sample size when population is more than 10,000 
$\mathrm{z}$ is the standard normal deviation set at 1.96, which corresponds to 95\% confidence level

$\mathrm{p}$ is the proportion in the particular population estimated to have a particular characteristic ( $50 \%$ is used since there is no reasonable estimate)

$\mathrm{q}$ is $1.0-\mathrm{p}=0.50$

$\mathrm{d}$ is the degree of accuracy desired. Usually set at 0.05 or 0.02 .

Applying the values in this study

$$
\mathrm{n}=\frac{1.96^{2} * 0.50 * 0.50}{(0.05)^{2}}=384.16
$$

Since the population of pregnant women attending antenatal clinic in St Philomena's Hospital is less than 10,000

The sample size for this study will be

$$
\mathrm{nf}=\frac{\mathrm{n}}{1+(\mathrm{n} / \mathrm{N})}
$$

Where $\mathrm{nf}$ is the desired sample size when population is less than 10,000

$\mathrm{n}$ is the desired sample size when population is more than 10,000

$\mathrm{N}$ is the estimate of the population size.
Applying the values for these estimates,

$$
\mathrm{nf}=\frac{384}{1+384 / 2000}=\frac{384}{1.192}=322.15 .
$$

Therefore, the sample size for pregnant women for the determination of glucose tolerance status will be 322

Data analysis was done by cross-tabulation and percentages.

\section{Results}

The prevalence rate for fetal macrosomia in St Philomena's Hospital was $8.4 \%$ within the study period (Table 1). Cesarean section rate for all deliveries within the study period was $20.5 \%$ while the specific cesarean section rates for macrosomic and non-macrosomic babies were $39.2 \%$ and $18.8 \%$ respectively (Table 2 ).

The favorite foods were white rice, cooked fermented cassava, pounded yam and beans for $40 \%, 30.6 \%, 20 \%$ and $9.3 \%$ of the mothers of macrosomic babies respectively (Table 3). All mothers of macrosomic babies indulged in sugary beverages on daily basis with $60 \%$ of the mothers preferring soft drinks and $40 \%$ of the mothers preferring sugar sweetened cocoa drinks (Table 4).

Table 1. Prevalence of Fetal Macrosomia in St Philomena's Hospital, Benin City

\begin{tabular}{|l|c|}
\hline No of deliveries within the Study Period & 2410 \\
\hline No of fetal macrosomia & 79 \\
\hline Prevalence of Fetal Macrosomia & $8.4 \%$ \\
\hline
\end{tabular}

Table 2. Cesarean Section Rates in Macrosomic and Non-macrosomic Childbirths in St Philomena's Hospital (April 2014 to March 2016)

\begin{tabular}{|l|c|c|}
\hline & Fetal macrosomia & Non-macrosomic babies \\
\hline No of deliveries & 202 & 2208 \\
\hline No of Cesarean sections & 79 & 415 \\
\hline Cesarean section rate & $39.2 \%$ & $18.8 \%$ \\
\hline
\end{tabular}

Table 3. Nutritional habits of mothers of macrosomic babies in Benin City, Nigeria

\begin{tabular}{|l|c|c|}
\hline Favorite food & No of mothers & Frequency of intake/week \\
\hline White rice & $30(40 \%)$ & $>7$ \\
\hline Pounded Yam & $15(20 \%)$ & $>7$ \\
\hline Cooked Fermented Cassava & $23(30.6 \%)$ & $>6$ \\
\hline Beans & $7(9.3 \%)$ & $>7$ \\
\hline Total & $75(100 \%)$ & \\
\hline
\end{tabular}

Table 4. Beverage Drinking Habits of Mothers of Macrosomic Babies in Benin City, Nigeria

\begin{tabular}{|l|c|c|}
\hline Favorite Sugary Beverages & No of mothers & Frequency per week \\
\hline Soft drinks & $45(60 \%)$ & $>7$ \\
\hline Cocoa drinks with sugar & $30(40 \%)$ & $>7$ \\
\hline Total & $75(100 \%)$ & \\
\hline
\end{tabular}

Table 5. Vegetable Eating Habits of Mothers of Macrosomic Babies in Benin City, Nigeria

\begin{tabular}{|l|c|c|}
\hline Addition of Vegetable to food & No of mothers & Percentage \\
\hline Regular use & 15 & $20 \%$ \\
\hline Occasional use & 20 & $27 \%$ \\
\hline Nil & 40 & $53 \%$ \\
\hline Total & 75 & $100 \%$ \\
\hline
\end{tabular}


Table 6. Knowledge of glucose tolerance status by pregnant women in Benin City, Nigeria

\begin{tabular}{|l|c|c|}
\hline Group & Antenatal women & Mothers of Macrosomic Babies \\
\hline Quantity & 330 & 75 \\
\hline Performed FBG & $27(8.2 \%)$ & $5(6.7 \%)$ \\
\hline
\end{tabular}

Only $20 \%$ of mothers of macrosomic babies regularly added vegetables to their food while $27 \%$ of the mothers occasionally added vegetable to their food (Table 5).

Only $8.2 \%$ and $6.7 \%$ of the pregnant women and mothers of macrosomic babies respectively were aware of their fasting blood sugar status (Table 6).

\section{Discussion}

Fetal macrosomia accounted for $8.4 \%$ of deliveries in St Philomena's Hospital within the study period. This was within the range of 3\%-15\% reported by Muhamadbeigi et al., (2011) [20]. It was also consistent with rates reported by other studies in southern Nigeria but it was higher than the rate reported in similar study in the University of Benin Teaching, Benin City where Olokor et al., (2015) [19] found a prevalence rate of 5.4\%. This intra-city variation in prevalence rate may be due to the higher clientele in St. Philomena's Hospital due to easier accessibility and affordability. In Nigeria, prevalence of fetal macrosomia seems to vary according to the geographical regions. While it is higher in the rain forest regions in the southern parts of Nigeria, [19,21,22] it is relatively less in the savannah regions of Northern regions [23]. The variations in prevalence according to geographical region may be suggestive of dietary factors and cultural habits as predisposing factors of fetal macrosomia. The prevalence of fetal macrosomia has been reported as 8.1\% in Enugu, Eastern Nigeria, [21] 7.4\% in Port Harcourt, South-south, Nigeria [22] (On 5.4\% in Benin City, South -south, Nigeria [19] and 4.2\% in Zaria, Northern Nigeria [23].

In this study, most of the mothers of macrosomic babies indulged in regular intake of foods and beverages that may be regarded as high glycemic index diets without the use of dietary fiber in form of vegetables. Only $7 \%$ of the mothers of macrosomic babies had beans as their favorite food while $53 \%$ of these mothers had never added dietary fiber in form of vegetables to their diet. Furthermore, all mothers of macrosomic babies indulged in sugary drinks on a regular basis. This habit becomes significant when it is realized that excessive intake of high glycemic index diets increases the quantity of post digestion glucose available for absorption. This in turn boosts insulin secretion from the pancreas with consequent anabolic process and adipose tissue accretion. [24,25] Apart from causing pre-gravid obesity in the non-pregnant; it also predisposes pregnant women to develop excessive gestational weight gain, both of which are predisposing factors of fetal macrosomia. [26,27] The addition of vegetable to high glycemic index diets reduces post digestion absorption of glucose, [28] with consequent modulation of fat accretion. Leguminous foods such as beans have low glycemic index. Naturally fiber-rich foods such as beans and raw pears slowly increase blood glucose and thus have far lower glycemic indexes, of approximately 29-38.9. [29] Addition of cooked beans to high glycemic index foods such as white rice may therefore be useful in modulating glucose absorption during pregnancy with the aim of preventing fetal macrosomia.

In this study, it was found that most of the mothers of macrosomic babies had never been tested for fasting blood glucose; only $6.7 \%$ of the mothers of macrosomic babies and $8.2 \%$ of the pregnant women visiting the antenatal clinic had been tested for fasting blood glucose. Fasting blood glucose is not yet a routine antenatal test in most hospitals in Nigeria. With increasing incidence of diabetes mellitus [30], routine antenatal fasting blood glucose will become a necessity especially when it is known that diabetes mellitus is a major risk factor for fetal macrosomia in most parts of the world. [31]

Though it is now known that sugary beverages contribute to the development of obesity, [32,33] it is not uncommon to find advertisements in the print and electronic media in Nigeria asking people, making no exceptions for pregnant women, to drink a bottle of sugary beverage such as 'malt' drinks every day of the week. In this study, it was found that all mothers of macrosomic babies interviewed indulged in the consumption of sugary beverages on daily basis. Even those mothers whose favorite food was beans had macrosomic babies probably because of the daily consumption of sugary beverages. Sugary beverages enhance insulin secretion. High level of Insulin inhibits leptin, depressing satiety and facilitating the development of obesity. [34] In the fetal compartment, there is also increased fat mass, increased muscle mass and longitudinal bone growth [35], a factor, which favors the development of shoulder dystocia during labor. Therefore, when there is excessive secretion of insulin in pregnancy as is found in insulin resistance and maternal over-nutrition, the result is excessive gestational weight gain and large babies.

The cesarean section rate in St Philomena's Hospital during the study period was 20.5\%. When cesarean sections for fetal macrosomia are excluded, the cesarean section rate drops to $18.8 \%$. This rate is above the recommended rate of $10-15 \%$ by World health Organization. [1] Though the increase in cesarean section rate due to fetal macrosomia may be a paltry $1.7 \%$ in this study, this is significant when the human and material resources necessary for the 79 cases of fetal macrosomia is considered especially as it may mean catastrophic care for many of the mothers. It is also noteworthy that the cesarean section rate among the cases of fetal macrosomia was as high as $39.2 \%$. By implication, as the prevalence of fetal macrosomia rises in a community, cesarean section rate is expected to rise significantly. World Health organization is already worried about the escalating cesarean section rates in several parts of the world. When the need for cesarean section becomes too high in medically underserved areas, the increase in maternal mortality rates in such communities can best be imagined. It is therefore of utmost importance to nip the increasing incidence of fetal macrosomia in Nigeria in the bud. 
Since predisposing factors for fetal macrosomia are known, strategies for preventing fetal macrosomia may be as follows:

- Prevention of pre-gravid obesity

- Prevention of excessive gestational weight gain

- Early diagnosis and treatment of diabetes mellitus

- Specific protection for fetal macrosomia

\subsection{Prevention of Pre-gravid Obesity and Excessive Gestational Weight Gain}

A macrosomic female baby has the potential of developing obesity, insulin resistance, hyperlipidemia and hypertension making it an independent risk factor for the development of metabolic syndrome in adulthood. [36] Therefore the prevention of fetal macrosomia is itself a conducive step in the prevention of pre-gravid obesity. Women of reproductive age should be encouraged to 'watch their weight' by not eating more than enough of available food especially when these are high glycemic index diets. There should be no 'second helpings' and quantity of energy intake should not be more than 2000 Kilo calories per day. Diets containing beans and dietary fibers in form of vegetables and fruits should be encouraged. Adequate exercise is a necessity. Sugary beverages should be minimized if they cannot be avoided.

\subsection{Prevention of Excessive Gestational Weight Gain}

The Institute of Medicine (IOM) prescribes a range of weight gain for normal, overweight and obese pregnant women and also recommends cut off values for excessive gestational weight gain. [37] This implies that obese women should eat less food than women with normal weight during pregnancy in order to attain recommended gestational weight gain. According to the Institute of Medicine's recommendations, a pre-gravid obese woman with a body mass index greater than $30 \mathrm{Kg} / \mathrm{m}^{2}$ should maintain an average gestational weight gain of 0.17 to $0.27 \mathrm{Kg}$ per week of pregnancy while a pre-gravid overweight woman with a body mass index of 25.0-29.9 $\mathrm{kg} / \mathrm{m}^{2}$ should maintain an average gestational weight gain of 0.23 to $0.33 \mathrm{Kg}$ per week. A woman with a normal pre-gravid body mass index (18.5-24.9 kg/m²) should maintain an average gestational weight gain of $0.35-0.50 \mathrm{Kg}$ per week. [38] The habit of eating low glycemic index diets, inclusion of dietary fibers in the diet and avoidance of sugary beverages is very useful in successful maintenance of desired gestational weight gain.

\subsection{Early Diagnosis and Treatment of Diabetes mellitus}

Fasting blood glucose should be made a routine antenatal test in Nigeria to enable early diagnosis and treatment of diabetes mellitus. This test should be carried out in all trimesters of pregnancy in order to detect cases of gestational diabetes mellitus. When diabetes mellitus is detected, affected patients should be managed jointly by the obstetrician and internal physician with special interest in the management of diabetes mellitus. In Nigeria, it is not uncommon to find cases of complicated diabetes mellitus in pregnancy being managed by quacks, wives of religious leaders, and health care providers, who are not experienced in its management. This calls for legislation on the right of various categories of health care providers or facilities to conduct delivery for various categories of pregnant women.

\subsection{Specific Protection for Susceptible Women}

Where women have developed the predisposing factors for fetal macrosomia, it becomes necessary to offer a specific protection for its prevention. In a previous study, it was found that intraperitoneal injection of aqueous extract of alligator pepper was capable of reducing gestational weight gain and litter size of pregnant Sprague Dawley rats without adverse effects on the mother rats and the off springs. [39] This effect was also observed in alloxan induced diabetic Sprague Dawley rats in another study. [40] In yet another study, it was suggested that the active constituent of the alligator pepper with this activity is Beta caryophyllene. [41] Apart from alligator pepper, beta caryophyllene is a common constituent of the essential oils of numerous spice and food plants and a major component in cannabis [42] Beta-caryophyllene is a known type 2 cannabinol receptor agonist (CB2R), which can reduce weight by lipo-oxidation. [43] as well the metabolic effects of its insulin reducing property in the first trimester of pregnancy. [41] This observation could be used in the design of a vaccine or food supplement, which could be used as specific protection for susceptible pregnant women.

\section{Conclusion}

Fetal macrosomia may become an important factor in increasing cesarean section rates especially when obesity is becoming a pandemic. [44] The ingestion of high glycemic index foods as well as sugary beverages has been suggested as a contributory factor of fetal macrosomia in Nigeria. [45] This implies that fetal macrosomia is a preventable condition. It is therefore possible, using preventive methods, to reduce the incidence of fetal macrosomia with the aim of reducing escalating cesarean section rates in areas where facilities for cesarean section are available or reducing unprecedented maternal mortality rates in areas where such facilities are not available.

\section{Significance to Public Health}

Fetal macrosomia is a preventable, non-communicable condition, which increases obstetric intervention rates including cesarean section rate. Furthermore, it increases maternal morbidity and mortality rates. The risk factors of fetal macrosomia such as diabetes mellitus, gestational diabetes mellitus, pre-gravid obesity and excessive gestational weight gain are either controllable or preventable in various stages of prevention including health education and promotion, specific protection and early diagnosis and treatment. Complications such as 
shoulder dystocia, birth trauma, birth asphyxia and maternal trauma such as perineal tears and obstetric fistulae are common complications, which increase disability rates among women. In medically underserved areas, fetal macrosomia escalates maternal morbidity and mortality rates. This research highlights the preventable nutritional and metabolic risk factors of this condition and establishes its effect on cesarean section rates, emphasizing that its preventable nature can be useful in reducing escalating rates of cesarean section, a procedure which not only has its complications but comes as a form of catastrophic care to many of impoverished women in Nigeria.

\section{Acknowledgements}

I wish to thank Mr. Austin Unuebho who assisted in the administration of questionnaires.

\section{Funding}

None.

\section{Conflict of Interest}

None.

\section{Ethical Approval}

This was obtained from the ethical committee of St Philomena’s Hospital, Benin City, Nigeria.

\section{References}

[1] WHO. World Health Organisation Statement on Caesarean Section Rates. 2015; 1-8.

[2] Timofeev J, Reddy UM, Huang, C., Driggers RW, Landy HL, Laughon SK. Obstetric Complications, Neonatal Morbidity, and Indications for Cesarean Delivery by Maternal Age. Obstet Gynecol 2013; 122(6): 1184-1195.

[3] Feng XL, Xu L, Guo Y, Ronsmans C. Factors influencing rising caesarean section rates in China between 1988 and 2008. Bulletin of the World Health Organization 2012; 90: 30-39A.

[4] Barros FC., Matijasevich A, Maranhão AGK, Escalante J J, Neto DLR, Fernandes RM, Vilella MEA, Matos AC, Albuquerque C, Ponce de Léon RG, Victora CG. Cesarean sections in Brazil: will they ever stop increasing? Pan American Journal of Public Health 2015; 38(3): 217-225.

[5] Hamilton BE, Martin JA, Osterman MJK. Curtin SC, Mathews TJ. Births: Final Data for 2014. National Vital Statistics Reports 2014, 64(12): 1-64

[6] Ugwu EOV, Obioha KCE, Okezie OA, Ugwu AO. (2011). A Five-year Survey of Caesarean Delivery at a Nigerian Tertiary Hospital. Ann Med Health Sci Res. 2011; 1(1): 77-83.

[7] Adekanle, D, Adeyemi A, Fasanu A. Caesarean section at a tertiary institution in Southwestern Nigeria-A 6-year audit. Open Journal of Obstetrics and Gynecology 2013; 3: 357-361.

[8] Hilekaan SKH, Ojabo A, Idogah S. Caesarean Section Rate in a Tertiary Hospital in Makurdi, North-Central Nigeria. General Med 2015; 3: 183.

[9] Daniel CN and Singh S. Caesarean delivery: An experience from a tertiary institution in north western Nigeria. 2016; 19(1):18-24.
[10] John CO. and Alegbeleye JO. Caesarean Delivery at a Teaching Hospital, South-South Nigeria: A Five-Year Review. IJTDH 2017; 27(2): 1-6.

[11] Minkoff, H. (2012). Fear of Litigation and Cesarean Section Rates. Seminars in perinatology 2017; 36(5): 390-394.

[12] Tollånes MC. Increased rate of Caesarean sections--causes and consequences. Journal of the Norwegian Medical Association (Tidsskr Nor Laegeforen) 2009; 129(13): 1329-1331.

[13] Sufang G, Padmadas SS, Fengmin Z, Brown JJ, Stones RW. Delivery settings and caesarean section rates in China. Bulletin of the World Health Organization.2007; 85(10): 733-820.

[14] Mishra US and Ramanathan M. Delivery related complications and Determinants of Cesarean section rates in India. Health Policy and Planning 2002; 17(1): 90-98

[15] Ortiz-Prado E, Acosta Castillo T, Olmedo-López M, Armijos L, Ramírez, D, Iturralde, AL. Cesarean section rates in Ecuador: a 13-year comparative analysis between the public and private health systems. Revista Panamericana de Salud Publica. (Pan American Journal of Public Health) 2017; 41:e15.

[16] Subedi S. Rising rate of cesarean section - a year review. Journal of Nobel Medical College. 2012; 1(2): 72-76.

[17] Population City Benin City - Population. http://www.population.gov.ng/images/Priority\%20table\%20Vol\% 204.pdf. Accessed on 29-04-2017.

[18] Araoye MO. Sample size determination. Research methodology with statistics for health and social sciences. 1st Ed. Ilorin: Nathadex Publishers 2004;115-120.

[19] Olokor OE, Onakewhor JU, Aderoba AK. Determinants and outcome of fetal macrosomia in a Nigerian tertiary hospital. Niger Med J. 2015; 56: 411-415.

[20] Mohammadbeigi A, Farhadifar F, Soufi zadeh N, Mohammadsalehi N, Rezaiee M, Aghaei M. Fetal Macrosomia: Risk Factors, Maternal, and Perinatal Outcome. Ann Med Health Sci Res. 2013; 3(4): 546-550.

[21] Ezegwui HU, Ikeako LC, Egbuji C. Fetal macrosomia: obstetric outcome of 311 cases in UNTH, Enugu, Nigeria. Niger J Clin Pract. 2011; 14(3):322-326.

[22] Onyearugha CN and Ugboma H. Macrosomia: Prevalence and predisposing factors as seen at a university teaching hospital, South-South Nigeria. J Med Investig Pract. 2014; 9: 12-15.

[23] Alsammani MA. and Ahmed SR. Fetal and maternal outcomes in pregnancies complicated with fetal macrosomia. North Am J Med Sci.2012; 4: 283-286.

[24] Bullock J. Biochemical actions of insulin. In: Bullock J, Boyle J, Wang C. (eds.). Physiology. 4th Edition. National Medical Series for Independent Study. Baltimore. Lippincott Williams and Wilkins 2003; 674-675.

[25] Barrett K, Barman M, Boitano S, Brooks HL. Endocrine Functions of the Pancreas and Regulation of Carbohydrate Metabolism. Ganong's Review of Medical Physiology. 24th Edition. New Delhi. Tata McGraw Hill. 2012; 431-451.

[26] Jensen DM, Ovesen P, Beck-Nielsen H, Mølsted-Pedersen L, Sørensen B, Vinter C, Damm P. Gestational weight gain and pregnancy outcome in 481 obese glucose tolerant women. Diabetes Care. 2005; 28(9): 2118-2122.

[27] Kim, SY, Sharma AJ, Sappenfield W , Wilson HG., Salihu HM Association of Maternal Body Mass Index, Excessive Weight Gain, and Gestational Diabetes Mellitus with Large-forGestational-Age Births. Contributions to Large-for-GestationalAge Births. Obstetrics and Gynecology 2014; 1-8.

[28] Queenan KM., Stewart ML, Smith KN. Concentrated oat betaglucan, a fermentable fiber, lowers serum cholesterol in hypercholesterolemic adults in a randomized controlled trial. Nutrition Journal. 2007; 66.

[29] de Munter JS, Hu FB., Spiegelman D, Franz M, van Dam RM. Whole grain, bran, and germ intake and risk of type 2 diabetes: a prospective cohort study and systematic review. PLoS Medicine 2007; 4:e261. 31.

[30] Chinenye, S. and Ekene, Y. State of Diabetes Care in Nigeria: A Review. The Nigerian Health Journal 2011; 11(4):101-106.

[31] Mayo Clinic Fetal Macrosomia:Risk Factors and complications 2017; http://www.mayoclinic.org/diseases-conditions/fetalmacrosomia/basics/risk-factors/con-20035423. Accessed on 14/04/201. 
[32] Vartanian. LR., Schwartz MB, Brownell KD.Effects of soft drink consumption on nutrition and health: a systematic review and meta-analysis. Am J Public Health 2007; 97:667-675.

[33] Te Morenga L, Mallard S, Mann J. . Dietary sugars and body weight: systematic review and meta-analyses of randomised controlled trials and cohort studies. BMJ 2013; 346:e7492.

[34] Lustig RH. Postnatal hyperinsulinemia, leptin resistance and Obesity. Obesity: Nature or Nurture. Lustig R. H ed. Obesity before birth. Maternal and Prenatal Influences on the Offspring. New York. Springer 2010; 8.

[35] Wang J, Zhou J, Bondy C1999; A. Igf 1 promotes longitudinal bone growth by insulin-like actions augmenting chondrocyte hypertrophy. The Federation of American Societies for Experimental Biology Journal 1999; 13: 1985-1990.

[36] Baur AR. Macrosomia http://emedicine.medscape.com/article/262679-overview Accessed on 29-04-2017.

[37] Restall A, Taylor RS, Thompson JMD., Flower D, Dekker GA, Kenny LC, Poston L, McCowan LME. Risk Factors for Excessive Gestational Weight Gain in a Healthy, Nulliparous Cohort. 2014 (ID 148391): 9 pages.

[38] Chen Z, Du J, Shao L. Prepregnancy body mass index, gestational weight gain, and pregnancy outcomes in China. International Journal of Gynecology \& Obstetrics 2010; 109(1): 41-44.

[39] Inegbenebor U, Ebomoyi MI, Onyia KA., Amadi K Aigbiremolen AE. Effect of Alligator Pepper (Zingaberaciae Aframomum meligueta) on Gestational Weight Gain. Nigerian J Physiol Sci. 2009; 24(2): 165-69.

[40] Ehiagwina E and Inegbenebor U. Effect of Aqueous Extract of Alligator pepper on the Litter size of Alloxan Induced Diabetic Rats. International Journal of Community Rresearch 2016; 5(3): 90-94.

[41] Inegbenebor U, Ebomoyi MI, Obika LFO. Determining the Physiological Basis of the Effects of Alligator Pepper in Pregnant Sprague Dawley Rats. Jacob’s Journal of Plant Biology 2016; 1(1): $1-7$.

[42] Gertsch J, Leonti M, Raduner S, RaIcz I, Chen JZ, Xie XQ, Altman $\mathrm{KH}$, Karsak M, Zimmer A. Beta-caryophyllene is a dietary cannabinoid. Proceedings of National Academy of Sciences of the United States of America 2008; 105(26): 90999104.

[43] Zheng X, Sun T, Wang X. Activation of type 2 cannabinoid receptors (CB2R) promotes fatty acid oxidation through the SIRT1/PGC-1 $\alpha$ pathway. Biochemical and Biophysical Research Communications 2013; 436(3): 377-81.

[44] WHO Controlling the global obesity epidemic. 2003; http://www.who.int/nutrition/topics/obesity/en/ Accessed on 28/04/2017

[45] Inegbenebor U and Ebomoyi M. Prenatal Nutrition and Fetal Macrosomia in Medically Underserved Areas. Journal of Nutritional Therapeutics.2012; 1(1): 91-95. 